\title{
Direct and indirect contacts between cattle farms in north-west England
}

\author{
M.L. Brennan*, R. Kemp, R.M. Christley
}

(1)

Epidemiology Group, Department of Veterinary Clinical Sciences, University of Liverpool, Neston, CH64 7TE, UK

\section{Abstract}

Little is known regarding the types and frequencies of contact that exist between farms and which of these may act as pathogen transmission routes; however it is likely that farms demonstrate considerable heterogeneity in such contacts. In this cross-sectional study, we explored the direct and indirect contact types and frequencies that exist between cattle farms within a region, focusing on potential routes of pathogen transmission. The owners/managers of 56 farms located in a $10 \mathrm{~km}$ by $10 \mathrm{~km}$ study area in north-west England were administered an interview-based questionnaire between June and September 2005. Information was obtained relating to contact types and frequencies, including those involving animal movements, equipment sharing between farms and any contractors or companies visiting the farms. The data was explored using hierarchical cluster analysis and network analysis. There was considerable variation between farms arising from different contact types. Some networks exhibited great connectivity, incorporating approximately $90 \%$ of the farms interviewed in a single component, whilst other networks were more fragmented, with multiple small components (sets of connected farms not linked with other farms). A range of factors influencing contact between farms were identified. For example, contiguous farms were more 
likely to be linked via other contacts, such as sharing of equipment, direct farm to farm animal movements and use of the same livestock dealers ( $\mathrm{p}<0.001, \mathrm{p}=0.02$ and $\mathrm{p}=0.1$, respectively).

The frequency of contacts was also investigated; it is likely that the amount of contact a farm receives from a company or contractor and whether or not biosecurity is performed after contact would impact on disease transmission potential. We found considerable heterogeneity in contact frequency and that many company and contractor personnel undertook little biosecurity. These findings lead to greater understanding of inter-farm contact and may aid development of appropriate biosecurity practices and control procedures, and inform mathematical modelling of infectious diseases.

Keywords: Contact; Network; Biosecurity; Cattle; Cluster analysis

* Corresponding author. Tel.: +44 (0)151 794 6027; fax: +44 (0)151 7946028. E-mail address: marnie.brennan@ liverpool.ac.uk (M.L. Brennan).

\section{Introduction}

Infectious disease transmission at the individual, herd and farm level relies on some form of contact, either direct or indirect. Veterinary texts published in the early 1900's recognised a cause and effect relationship between animal contact and disease (Anderson, 1998) and as early as the mid-eighteenth century, livestock producers recognised animal movements as important 
routes for the spread of disease (Woolhouse and Donaldson, 2001). Many diseases, such as bovine tuberculosis and foot and mouth disease (FMD) are likely to be spread by these movements (Gibbens et al., 2001; Gilbert et al., 2005; Woolhouse et al., 2005); this was clearly demonstrated during the early phase of the 2001 FMD outbreak in the UK (Ortiz-Pelaez et al., 2006). Other contacts may also result in transmission of infectious agents, including sharing of equipment, movement of people and vehicles and contact over/through fences with neighbouring stock; it has also been reported that wildlife and even wind can play a role in transmission between contiguous or proximate premises (Mikkelsen et al., 2003; Woodroffe et al., 2006).

Often there is little knowledge of what contacts (direct and indirect) exist between farms. As was highlighted by the FMD outbreak in the UK in 2001, local risk kernels are often used to model local transmission, as details of contacts between farms are not well known (Woolhouse and Donaldson, 2001; Webb, 2005). Studies conducted in The Netherlands, California and New Zealand have identified and quantified these contacts over time, particularly with regard to the potential spread of FMD. The number of contacts varies greatly when considering characteristics such as type of enterprise, size of farm and number of animals on farm. It was reported in California that there were approximately 11 direct animal contacts and 404 indirect contacts per farm over a two week period (Bates et al., 2001), which is substantially more than the 92 direct and indirect contacts per farm seen over the same length of time in the Netherlands (Nielen et al., 1996). In comparison, 50 contacts of people, animals and materials were reported over a 2 week period during a study in New Zealand (Sanson et al., 1993).

Such variability illustrates the structural complexity and heterogeneity of the contacts that exist between farms, some of which can be represented schematically (Fig. 1). This could potentially be described as a 'network' of contacts between farms which requires further exploration. 
Network analysis facilitates investigation of interactions between units of interest ('nodes', e.g. animals or farms) at the population and the individual level and enables identification of key nodes in terms of the connectivity individuals have within a population (Corner et al., 2003). By focusing on the most likely contact types and the most significant individuals within these networks, it is possible to consider how disease may be transmitted through a population (Christley et al., 2005). It has been suggested that farm-level heterogeneity is present for all animal movement patterns and to presume homogeneity is likely to be unrepresentative of actual movement patterns (Bigras-Poulin et al., 2006). Furthermore, models that assume random mixing can overestimate the size of an outbreak and underestimate the initial rate of transmission (Christley et al., 2005). Hence, network analysis can play a role in developing understanding of the topology of potential routes of disease transmission, and consequently may aid the design of effective surveillance and control programs (Woolhouse et al., 2005).

The aim of this study was to investigate the characteristics of the direct and indirect contact structure of cattle farms in a region and to explore the nature of such contacts using network analysis techniques.

\section{Materials and methods}

\subsection{Study population}

A $10 \mathrm{~km} \times 10 \mathrm{~km}$ area of north-west England was selected and the owners or managers of all known cattle farms were contacted by mail and invited to participate in this cross-sectional observational study. This area had been used previously in other studies by the University of Liverpool with good farmer compliance. Follow up phone calls were made to all farms to 
100 ascertain willingness to participate. Of those farms whose phone numbers were not available,

101 visits were assigned to determine farm details and whether participation was possible. Visits to

102 all willing farms were conducted and questionnaires completed.

103

$104 \quad 2.2$ Questionnaire

105

106 The questionnaire consisted of 191 questions which concentrated on determining the direct

107 and indirect contacts between farms (a copy of the questionnaire is available on request). This

108 included questions relating to animal movements on and off the farm and their destinations and

109 departure points, and questions relating to the sharing of equipment between farms, any

110 personnel coming on and off the farm and the types and frequencies of companies/contractors

111 coming onto the farm. Social contacts between farmers were also investigated.

112 Some questions were asked in regards to current biosecurity practices relating to shared

113 equipment and companies and contractors visiting the farm. Attitudes of the interviewees

114 towards 19 biosecurity practices were also explored; these practices were selected after review

115 of current practices, sourcing information from peer-reviewed papers, current advice from

116 various government bodies and grey literature.

117 The interview-based questionnaires were administered to owners/farm managers during July

118 - September 2005. All interviews were conducted by the first author. A pilot study involving six

119 cattle farms outside the study area was completed prior to the main study.

2.3 On-farm observations

122

123 During visits, maps of each farm were used to gather information regarding contiguous

124 neighbours and farm area, including additional premises used for stock. Boundaries and fence 
125 types bordering the farm were noted; boundary fields that were frequented by animals and had

126 fences which allowed potential contact (e.g. wire fences, gapped hedges) with neighbouring

127 animals (those owned by other farmers) were recorded. A single fence that was reported to not

128 permit nose-nose contact (e.g. double-fences, thick hedges) was selected randomly from those

129 on the main farm and was examined to ascertain the potential for nose-nose contact with

130 neighbouring stock.

131

2.4 Data management and analysis

The questionnaire was formatted using Verity TeleForm Version 9.1 (Verity Inc) and data managed using Microsoft Office Access 2003 (Microsoft Corporation). Agglomerative hierarchical cluster analysis was used to classify or group farms (or farmers) according to animal movements (direct to slaughterhouse, farm-farm or through markets and dealers), use of companies and contractors and attitudes to the 19 biosecurity practices. Ward's clustering method was used; this results in clusters with the fewest within-cluster sums of squares (based

140 on squared Euclidean distance) (Sharma, 1996). These groups were compared with regard to the variables used in the cluster analysis itself and with other farm-level variables using chi-squared tests (for categorical data) and the Kruskal-Wallis test (for continuous data). These statistical analyses were performed using SPSS 12.0.1 for Windows (SPSS Inc.).

144 To examine whether the probability of one contact type was associated with the probability of

145 another, we used the Quadratic Assignment Procedure (QAP) correlation function in Ucinet v6.135 (www.analytictech.com/). This method calculates the similarity between two network

147 matrices using the Jaccard coefficient (Hanneman and Riddle, 2005). One of the matrices is then

148 randomly permuted using the QAP and the Jaccard coefficient recalculated. We performed this

149 permutation 10,000 times in order to compute the proportion of times that the random measure 
150 is larger than or equal to the observed measure. All network structures were formed using

151 Ucinet v6.135 and NetDraw v 2.41 (NetDraw; www.analytictech.com/).

\section{Results}

\subsection{Response rate}

Questionnaires were completed on 56 out of 81 farms, giving a $68.3 \%$ response rate. Of the

159 farms not participating, seven had ceased trading or did not have cattle and three were shortly to

160 cease trading. One farmer could not be contacted despite several visits and phone calls; 13

161 declined to participate and one farmer could not make an appointment in the allotted project

162 time. Therefore, considering only those farms in the area which owned cattle and would be in

163 the foreseeable future, a 78.8\% compliance rate was achieved. The three farms that were shortly

164 to cease trading were excluded as we believed that their general farm contacts might not be

165 representative of a typical farm in this area. Excluding those farms that did not have cattle/had

166 ceased trading, 15 farms remained that were not interviewed. Of these farms, information solely

167 regarding enterprise was collected on ten by telephone or via external data sources; six dairy

168 farms, two mixed cattle farms, one beef farm and one heifer rearing farm declined to participate.

169 All results reported in the following sections are derived using data obtained from the 56

170 participating farms and relate to cattle unless otherwise specified.

171 
174 The majority of interviewed farms in the study area were dairy farms (36 farms), with 19 fat-

175

176

177

178

179

180

181

182

183

184

185

186

187

188

189

190

191

192

193

194

195

196

197 stock farms, 15 suckler herds, eight store-animal producers and three pedigree breeders. Almost one third of dairy farms had additional cattle enterprises outside of the dairy sector. The median size of each farm was 80.3 hectares (range 6 - 2428; Interquartile range (IQR) 48 - 137) and the median number of cattle per farm was 170 (IQR 104-320).

Eleven farms had other animal enterprises; eight farmed sheep, two produced turkeys and one kept laying hens. Of the eight farms that owned sheep, five farmers stated that they grazed cattle on the same pasture at the same time.

\subsection{Types of direct contact}

\subsubsection{Animal movements}

The most commonly reported mechanism for trading animals was through markets $(89 \%$ of farms), followed by trading directly with other farms (73\%), through dealers (50\%) and to slaughterhouses (50\%). Markets and dealers were used most frequently for the sale, rather than purchase of animals. Most farms trading with dealers used one dealer only. In contrast, most farms purchased animals directly from other farms. The majority of slaughterhouse movements were to a plant outside of the study area.

The combined 2-mode (having 2 types of node; farms and other organisations) animal movement network involving interviewed farms and named markets, dealers and slaughterhouses incorporated almost all of the farms in the study area into a single network component (Fig. 2; excludes farm-farm movements). The network visually exhibited a 'hub and spoke' structure, described as such due to its similarity with the spokes of a wheel surrounding a centre point or 'hub', in this case the local market within the study area. This market plays an 
important role in connecting the nodes within the network. Although most farms used a single market, one farm bought and sold stock through 5 different markets.

The 1-mode (one type of node only; farms) animal movement network involving farm-farm movements appeared substantially different to the previous network (Fig. 3a). This network was fragmented and involved many movements of animals from farms outside of the study area. Fragmentation of the network increased when only those animal movements between farms in the study area were considered (Fig. 3b).

The patterns of animal movements (M) were explored using hierarchical cluster analysis which suggested three main groups (Table 1). Farms in all groups purchased directly from other farms and traded with markets and slaughterhouses. Farms in group M1 were solely reliant on markets for sale of animals and didn't trade with dealers or sell direct to other farms. All group M2 farms used dealers and did not sell directly to other farms. Group M3 farms all sold directly to other farms and half used dealers. Although an uncommon practice generally, the hiring of animals onto a farm occurred in M1 and M2 farms, but was not undertaken by farms in M3. There was no evidence of differences between these groups in terms of hectarage, number of animals, types of enterprise or in the use of companies or contractors ( $p>0.1$ in all cases).

\subsubsection{Stock on the farm not owned by the farmer}

Twenty five percent of interviewed farms responded that they sometimes had other livestock species living on the farm which were not owned by them. Of these 14 farms, 11 had sheep and four had cattle from other farms. All of the sheep originated from premises in neighbouring counties and all except one group of cattle were from locations within the same county but outside of the study area. The remaining cattle source was located within the study area.

\subsubsection{Contiguous neighbours and boundary fences}


A proportion of the non nose-nose contact boundary fences were randomly selected and examined on 43 farms. The selected fences on 19 farms (44\%) were assessed to have no contact possible through them (Fig. 4). Of the fences that allowed contact, over $90 \%$ permitted contact along only $1-20 \%$ of their length. Each farming unit (main holding plus additional premises with stock) had an average of 7.3 neighbouring farms (median 7, range 1-17) and an average of 7.2 grazing fields with potential neighbouring stock contact (median 7, range 0-24). As some neighbouring farms did not use perimeter fields for grazing, the average number of neighbours with potential stock contact was 3.3 (median 3, range 0-10).

\subsection{Types of indirect contact}

\subsubsection{Equipment sharing}

Forty three percent of farmers stated they shared equipment with other farms, the majority of farms sharing only one item (63\%). Tractors, trailers and wagons were shared most commonly between farms, followed by machinery for harvesting and ploughing, and muck vehicles. Waste handling and feeding were nominated as the two most common tasks for which tractors were utilised.

$$
\text { The 1-mode network arising through sharing of equipment was fragmented and involved }
$$
many farms outside the study area and farms within the study area that were not interviewed (Fig. 5). This network involved 30 interviewed farms including six that did not nominate themselves as sharing equipment but that were nominated by other farms as doing so. Only two of the relationships between interviewed farms were reciprocal, suggesting considerable underreporting

Of the 24 farmers that reported sharing equipment, 12 stated that they did not perform any biosecurity before or after using the items. Of the remaining 12, five farmers lent items; two 
would clean on return and two would clean before lending the items, only one farmer did both.

249 Eight farmers reported borrowing equipment from others; five cleaned the items prior to returning them (one cleaned only one of the three items borrowed) and two before using them; again one did both. One farmer lent and borrowed equipment and is therefore included twice.

\subsubsection{Companies and contractors}

There was considerable variation between the number of farms visited by each type of company or contractor and the frequency with which these visits occurred (Fig. 6). A list of the companies and contractors enquired about can be seen in Appendix A. At the time of interview, each farm had a median of 14 individual contractors visiting their farm per year (IQR 12-16, range 6-22) resulting in a median of approximately 67 visits per month (IQR 36-80, range 4136).

The networks connecting farms varied greatly between the different companies and contractors. Many exhibited similar characteristics to the private veterinarian network (Fig. 7a) representing a few companies visiting a large proportion of the farms. Other networks were quite fragmented and had components linking 15 or less farms, such as the animal haulier network (Fig. 7b), with a greater number of companies visiting fewer farms.

Farmers were asked about the organisations that went into animal areas (areas where animals are situated or have access to) and whether biosecurity was performed either at the vehicle or

267 personnel level (always, sometimes or never) before leaving the farm. These specific organisations were examined due to the perceived difference in transmission risk according to their on-farm role. Those companies most likely to park in animal areas were muck spreaders (30 farms), deadstock collectors (26 farms) and hoof trimmers (17 farms). Of these, muck spreaders cleansed and disinfected vehicles always or sometimes after visits $20 \%$ of the time,

272 deadstock collectors $4 \%$ of the time and hoof trimmers $53 \%$ of the time. Those companies most 
273 likely to have personnel going into animal areas were private veterinarians (56 farms), deadstock

274 collectors (51 farms) and farm assurance advisors (39 farms). Of these groups, private

275 veterinarians cleansed and disinfected themselves always or sometimes after visits $100 \%$ of the

276 time, deadstock collectors $10 \%$ of the time and farm assurance advisors $90 \%$ of the time. It is

277 interesting to note that deadstock collectors figure in both groups and appear to be undertaking

278 biosecurity infrequently in both instances.

279 Cluster analysis was used to classify farms according to company/contractor usage (Table 2).

280 There was little evidence of clustering when considering all companies and contractors, whereas

281 three clusters (CC1, CC2, CC3) were evident when considering only those that entered stock

282 areas (Table 2). Private veterinarians visited all 56 farms and were therefore not included in the

283 analysis. In group CC3 all farms were visited by milk companies, hoof trimmers and farm

284 assurance advisors; when looking at farm enterprise and farm size these farms were exclusively

285 dairies and tended to be bigger farms than those in the other groups. None of the farms in group

286 CC2 were visited by trading standards officers and only a few used animal hauliers; these farms

287 were a mixture of dairies and beef fattening farms. A large proportion of farms in group CC1

288 were visited by government vets, trading standards officers and animal hauliers; these farms

289 were a mixture of dairies, beef suckler and store cattle farms. There was no difference between

290 the groups with regard to types of animal movements (dealers, markets, farm-farm or direct to

291 slaughterhouse, $\mathrm{p}>0.2$ in all cases $)$ or herd size $(\mathrm{p}=0.2)$.

292

\section{3.4.3 Attitudes to biosecurity}

294 Attitudes of farmers to 19 biosecurity practices were examined by asking each farmer if they

295 thought each practice was very useful, useful or not very useful. A list of these biosecurity

296 practices can be seen in Appendix B. To explore if there were attitudinal similarities between

297 different farmers we again used hierarchical cluster analysis. It appeared that there were three 
main groups (B1, B2, B3); group B1 were more likely to respond that the biosecurity practices were useful ( $n=19)$, group B2 were more likely to respond that the biosecurity practices were very useful $(n=14)$ and group B3 were more likely to respond that the practices were not very useful ( $n=23)$. This suggested three main attitudes - one tending to be very optimistic or very positive, one optimistic or positive and the other negative or ambivalent.

To further explore this concept, we compared the biosecurity attitude clusters to the animal movement clusters and the company and contractor clusters. There was no significant association between farmers attitudes to biosecurity and their animal trading patterns $(\mathrm{p}=0.3)$.

The company and contractor groups varied with regard to their attitudes to biosecurity $(\mathrm{p}<0.1)$; there was a significant trend for group $\mathrm{CC} 2$ to have more positive attitudes towards biosecurity, compared to group $\mathrm{CC} 1\left(\chi^{2}\right.$ for trend $\left.\mathrm{p}=0.04\right)$. However, no difference was detected between groups $\mathrm{CC} 1$ and $\mathrm{CC} 3$, or $\mathrm{CC} 2$ and $\mathrm{CC} 3$.

\subsubsection{Employees and social contacts}

312 Eighty two percent of farms employed other workers. Just under half of these farms (44\%)

313 had employees that worked on other farms and approximately $26 \%$ had employees that ran their own cattle enterprise.

315 Social interactions which involved visiting other farms were investigated as part of the movement of people between premises. Farmers were asked to identify contacts with contiguous

317 neighbours, and with other farms. Forty one farmers (73.2\%) responded that they regularly

318 socialised with one or more of their contiguous neighbours. Thirty two $(57.1 \%)$ farmers

319 responded that they regularly socialised with people from other farms which were not 320 contiguous. 
323

324

325

326

327

328

329

330

331

332

333

334

335

Fifty percent of the farmers had additional farms or other pieces of land separate to their main holding on which cattle were run. Of these 28 farms, 19 had one additional premise, five had two additional premises, two had three additional premises and two had four additional premises.

\subsection{Network correlations}

Relationships between different networks were examined using QAP correlation. Those that showed significant similarities $(\mathrm{p} \leq 0.1)$ can be seen in Table 3 . Contiguous farms were more likely to be linked via various other types of contact. These included sharing of equipment and social interactions ( $\mathrm{p}<0.001$ for both). Contiguous neighbours were also more likely to move animals using the same markets $(\mathrm{p}=0.01)$ and dealers $(\mathrm{p}=0.1)$, and to have direct farm to farm movements $(\mathrm{p}=0.02)$. In addition, equipment sharing and farm-farm movements $(\mathrm{p}=0.05)$, equipment sharing and social interactions $(\mathrm{p}<0.001)$ and farm-farm movements and social interactions $(\mathrm{p}<0.001)$ were significantly correlated.

\section{Discussion}

The aim of this study was to investigate the characteristics of direct and indirect contacts arising between cattle farms which may potentially facilitate pathogen transmission. Broadly, these contacts arise due to the movement of animals, people, equipment or vehicles, or due to proximity. We have identified considerable variation in these contacts and in the structure of the networks arising from these contacts. 


\subsection{Study design and response rate}

This study was set in a lowland farming area of north-west England. Lowland farms typically have a greater number of dairy cows than in other areas of England (DEFRA, 2005b); the average number of dairy cows per holding in 2005 was 99 (DEFRA, 2006). In 2003 the north-west region contained the highest percentage of total dairy farms in the UK (29\%) when compared with the south-west (24\%), the north and north-east (18\%) and the south (16\%) (DEFRA, 2005c). The average number of dairy cows per farm in our study area was 220 (median 170) which reflects higher dairy cow density than the overall country average. This may result in a greater frequency of contacts than in other regions; however the types of contacts are potentially similar across the country. Therefore it is possible that the results of this study could be extrapolated, with caution, to other dairy regions. For areas where other types of cattle enterprise predominate it is likely that contact types and frequencies would vary, however the majority of contacts we have addressed, such as those involving animal movements, certain companies and contractors and personnel would still be likely to occur.

The study achieved a good response rate. This may be due to this area being used previously in other studies conducted by the University, or the reasonably short time commitment required of the farmers for participation. The effect of the non-participatory farms is unknown, although the farms that did not want to take part were found to be typical of those in the area in terms of enterprise suggesting that their activities would be somewhat similar to those interviewed. In terms of network structures the inclusion of these farms would have been invaluable in structuring more complete networks; it may be that some of the networks would be more connected with fewer, but larger, components. Observation of partial networks is an issue in this study; interviewed farms were able to nominate farms outside of the study area and as these 
372

373

374

375

376

377

378

379

380

381

382

383

384

were not interviewed their contacts were not included. Such "boundary effects" are common in network analysis, particularly where a small part of a much larger population is studied. However, all parameters only refer to the behaviours of interviewed individuals in the study area; we have not used network-level parameters. Therefore the results are valid for the population described.

\subsection{Types of direct contact}

\subsubsection{Animal movements}

We investigated patterns of animal movement between farms and other locations. Most farms in the study area were part of a single network component, linked via markets, dealers and slaughterhouses. The market within the study area acted as a "hub" and may facilitate pathogen transmission through this area. This network shows similar characteristics to other studies on the topology of animal movement networks within Great Britain (Robinson and Christley, 2007). Although most farms traded with a single market, one farm traded with five markets, potentially increasing the exposure of the network to farms in a wider geographic area. The trading of animals is a fundamental activity in livestock farming. However, farmers are able to make choices with regard to the mechanisms through which they trade animals. We used cluster analysis to classify farms according to their animal trading activities, resulting in three main groups. These groupings, which could not be explained by simple measures of farm type (hectarage, number of animals, enterprise), suggest that other factors such as previous experience contribute to a farmer's decision-making process with regard to the sale and purchase of animals. Given the recent trend in the UK toward increased reliance on markets for 
395

396

397

398

399

400

401

402

403

404

405

406

407

408

409

410

411

412

413

414

415

416

movement of animals and a concomitant decrease in farm to farm movements (Robinson and Christley, 2007), further investigation of the motivations underlying such decisions is warranted. This trend is concerning as it is well established that trading through markets or dealers leads to an increased risk of disease transmission; this can be due to commingling of animals from various sources or factors such as transport increasing stress levels potentially exacerbating latent disease conditions (Duncan, 1990; Barrington et al., 2006). The fact that the majority of farms in our study area used markets to sell stock and subsequently purchased directly from other farms would be likely to reduce the disease transmission potential in this region.

\subsubsection{Stock on the farm not owned by the farmer}

Agistment of stock (i.e. the housing/feeding of animals on pasture for payment) for other farmers was not an uncommon practice. Approximately two-thirds of the agisted stock were sheep, and whilst sheep do not transmit many cattle diseases, pathogens such as Salmonella dublin and viruses causing conditions such as malignant catarrhal fever can potentially be transferred between these species. Most of the agisted animals originated within the same county or neighbouring areas. Sending sheep from upland farms to lowland farms to be away-wintered has been a common farming practice over the past 150 years in Scotland and Wales (Jones, 1946); however it is difficult to find any recent studies investigating this practice. DEFRA has reported that pathogen transmission can occur between farms due to away-wintering of sheep (DEFRA, 2005a); the disease potential risks associated with practices such as these require further investigation. 
The potential for transmission of pathogens across farm boundaries depends on many factors, including the type of perimeter fence existing between farms and stock concentrations on neighbouring farms. Prevention of nose-to-nose contact across farm boundaries has been widely recommended as a means of improving herd biosecurity (Duncan, 1990; SAC, 2002). In the current study, while many boundary fences perceived to prevent contact actually did so, nose-tonose contact was possible with animals on adjacent farms in more than half. In most cases this contact was possible over a relatively small proportion of the total length of the fence. The effect of these contact points on the potential for disease transmission will depend on the proportion of time animals spend at fence lines and their behaviour during this time which requires further investigation. However, it is likely that such contact points reduce efficacy of these fences in terms of prevention of disease transmission.

\subsection{Types of indirect contact}

\subsubsection{Equipment sharing}

Almost half the farmers shared equipment with other farms and importantly, tractors were the most commonly shared item, farmers reporting that tractors were most frequently used for waste handling and feeding. This potentially increases the risk of pathogen transmission by the faecaloral route. Therefore, application of appropriate biosecurity measures may be important in

437 limiting this mode of transmission. Most farmers who borrowed equipment chose to clean and disinfect items only before returning them, suggesting that the cleaning process may have more to do with other factors (such as politeness) than concern over biosecurity. It is documented that contamination of equipment with mucus, faeces and blood can harbour organisms such as 
441 Salmonella and Mycobacterium species; it is recommended that borrowed or hired equipment

442 should be cleaned and disinfected before it is used (Caldow et al., 1998). Although the majority

443 of farmers did not disclose that they shared equipment, there was evidence of underreporting of

444 this contact, suggesting that it may be a more important route of transmission than indicated by

445 our data. Furthermore, many producers did not appear to undertake cleaning and disinfecting of

446 shared equipment, increasing the potential importance of this network in facilitation of disease 447 transmission.

\subsubsection{Companies and contractors and attitudes to biosecurity}

The number and frequency of companies and contractors visiting farms in this area was substantial, suggesting that a median farm would have (on average) more than two visits per day by personnel from an external contractor or company. Similar to the animal movement networks, the networks arising through contact with specific companies and contractors exhibited considerable heterogeneity. Several networks had only a few contractors or companies contacting many farms within the study area. Others had a more fragmented pattern, with more companies or contractors contacting only a few farms in the region. These differing patterns are likely to reflect both the geographical range of the companies' and contractors' activities and the differing number of farms they attend. It is also likely that those organisations having contact with stock or going into areas where stock have access to will be of greater risk of facilitating disease than those that do not. When considering biosecurity practices it appears that deadstock collectors could be high risk; they clean and disinfect vehicles and personnel infrequently on 462 many of the farms in the study area and are likely to have contact with diseased animals. The

463 fact that muck spreaders visit more than half of the farms in the study area yet only cleanse and 464 disinfect their vehicles infrequently is of concern considering the many diseases which are 
465 transmitted via faecal material. It is reassuring that private veterinarians and farm assurance

466 advisors appeared to cleanse and disinfect on the majority of farms; these professions should act

467 as advisors regarding disease preventative practices. The risk posed by a company of disease

468 transmission between farms ultimately will be a function of the number of farms visited, the

469 probability that they act as a fomite for a particular pathogen, and their frequency and efficacy of 470 biosecurity.

471 Cluster analysis suggested three farm categories on the basis of company and contractor 472 usage. Broadly, this classification system divided farms according to enterprise and farm size, 473 although it was not possible to group farms solely using these characteristics. This highlights 474 the difficulties of classifying farms, differences in individual management practices and 475 activities varying significantly between farms. Cluster analysis allows us to categorise farms 476 according to the types of visits they have or movements they undertake. This approach may 477 provide useful insight for herd health specialists in terms of disease transmission prevention and may help to inform strategies for interventions when determining legislation on issues such as biosecurity and food safety or setting restrictions during exotic disease outbreaks. It may also 480 help in developing categories of farm type for refinement of mathematical models of pathogen 481 transmission.

When comparing the company and contractor clusters with the biosecurity clusters, farms in $483 \mathrm{CC} 2$ tended to have a more positive attitude to biosecurity, compared to those in $\mathrm{CC} 1$. The farmers with the least positive attitudes to biosecurity (CC1) were those most likely to be visited by government veterinarians and Trading Standards officers; whilst those with a more positive attitude tended to be visited by fewer types of external companies and contractors. The cause of these apparent relationships is unknown and the reasons for these associations require further investigation. 


\subsubsection{Employees and social contacts}

491

492

494

495

496

Most farmers in this study area employed people to work on their farms; many of these employees also worked on other farms and/or kept cattle of their own. This finding is in keeping with the current socio-economic trend in the farming community of greater numbers of part-time employees (MAFF, 1998). Although the movement of people for work may aid dissemination of ideas and innovation throughout the farming community, people may act as fomites, particularly when minimal biosecurity is performed. In a previous study, Dutch dairy farms that employed temporary workers who worked on other farms were 3.3 times more likely to be positive for Bovine Herpes Virus 1 (van Schaik et al., 1998). This potential risk is also present for social contacts, although there may be a low probability of disease transmission during a social visit unless animals or animal areas are frequented. Nielen et al. (1996) in The Netherlands reported that social visits were responsible for a substantial amount of contact between livestock farms; visitors had contact with farm animals during $25 \%$ of these visits.

\subsubsection{Additional premises}

In this study, half the farms had additional premises for keeping stock and the majority of these had only one additional premise. The use of additional farms or land parcels affects the potential for farms to be in direct contact with other farms, and may increase the geographic range of this contact, particularly when the additional premise is in a separate location to the main premise. In our study several of the farms had additional premises adjacent to their main holding, sometimes only separated by a gate and managed as a single unit. In this situation, the geographic range of this contact is unlikely to be increased. 
514 Whilst contiguous neighbours were clearly linked via common boundaries and general

515 proximity, such farms were also more likely to share other contacts, such as equipment sharing,

516 farm-farm animal movements and social interactions. This suggests that contiguous and local

517 contacts are multi-dimensional. Some of these relationships may be expected; farms that are

518 contiguous are probably more likely to establish social relationships, facilitating sharing of

519 equipment and potentially transmission of infectious agents via vehicles and personnel. In

520 addition, information regarding sale prices and recommendations of stock from particular

521 sources may be communicated within these social groups. Social contagion theory suggests that

522 individuals can adopt the attitudes or behaviours of others in the social network with whom they

523 communicate (Scherer and Cho, 2003); it may be this has some influence on farmer risk

524 perception in terms of trading with particular farms, dealers and markets and even attitudes

525 towards biosecurity. These similar risk perceptions could, in addition, work in parallel with the

526 cluster analysis groupings of farms with similar trade patterns and attitudes, and may assist with

527 the development of information dissemination tools in regards to herd health and disease

528 prevention. Whilst the role of different contact mechanisms in pathogen transmission is

529 pathogen specific, disentangling the components of "local contact" may suggest specific

530 interventions to reduce transmission via this otherwise undefined mechanism. 
535 Contact between farms on a local scale demonstrates considerable heterogeneity; variation exists between farms, between contact types and in the structure of the networks arising through these contacts. Such variation may impact on the farm-level risk of pathogen transmission. Despite this, there have been few investigations addressing these issues. Ideally producers and herd health professionals would design tailored biosecurity programs to limit "risky" contacts on

540 each holding. In the UK this is, to some extent, carried out by private veterinarians, farm assurance advisors and other health professionals. However, such programs focus only on certain endemic diseases. Furthermore, individual farm programs are unlikely to be appropriate during exotic disease outbreaks; similarly it is difficult to design policies for utilization during epidemics that will be relevant to all farming situations. In this study we have highlighted

545 certain features which may be typical of other dairy areas in the UK. We have also suggested a number of farm "types" based on contact patterns. Studies such as these in targeted or selected

547 areas of the country may bridge the gap between blanket recommendations and farm-level 548 programs and may be informative for risk managers addressing exotic and endemic disease

549 risks. Further research is required in order to determine the extent to which these concepts can 550 be extended to the wider UK farming community.

\section{Acknowledgements}

Many thanks to all the farmers involved with this project including those who assisted with the pilot study without whom this research would not have been possible. We thank DEFRA and HEFCE for funding this project (grant VTRI VT0103). MB received a RCVS Trust travel scholarship to present this work at the 2007 Society for Veterinary Epidemiology and Preventive 


\section{References}

563

Anderson, J.F., 1998. Biosecurity - A new term for an old concept - How to apply it. Bov. Pract. 32, 61-70.

Barrington, G.M., Allen, A.J., Parish, S.M., Tibary, A., 2006. Biosecurity and biocontainment in alpaca operations. Small Ruminant Res. 61, 217-225.

Bates, T.W., Thurmond, M.C., Carpenter, T.E., 2001. Direct and indirect contact rates among beef, dairy, goat, sheep, and swine herds in three California counties, with reference to control of potential foot-and-mouth disease transmission. Am. J. Vet. Res. 62, 11211129.

Bigras-Poulin, M., Thompson, R.A., Chriel, M., Mortensen, S., Greiner, M., 2006. Network analysis of Danish cattle industry trade patterns as an evaluation of risk potential for disease spread. Prev. Vet. Med. 76, 11-39.

Caldow, G.L., Crawshaw, M., Gunn, G.J., 1998. Herd health security in the suckler herd. Cattle Pract. 6, 175-179.

Christley, R.M., Pinchbeck, G.L., Bowers, R.G., Clancy, D., French, N.P., Bennett, R., Turner, J., 2005. Infection in social networks: Using network analysis to identify high-risk individuals. Am. J. Epidemiol. 162, 1024-1031.

Corner, L.A.L., Pfeiffer, D.U., Morris, R.S., 2003. Social-network analysis of Mycobacterium bovis transmission among captive brushtail possums (Trichosurus vulpecula). Prev. Vet. Med. 59, 147-167.

DEFRA, 2005a. Reports of Salmonella in cattle. http://www.defra.gov.uk/corporate/vla/science/documents/sci-salm05-chp2-1.pdf.

DEFRA, 2005b. Review of the Agricultural and Horticultural Levy Bodies - Final Report. http://www.defra.gov.uk/farm/policy/levy-bodies/pdf/levy-radcliffe-review.pdf.

DEFRA, 2005c. A study of the long-term trends affecting the farming industry. http://www.defra.gov.uk/farm/policy/regulation/charge/pdf/long-term-trends.pdf.

DEFRA, 2006. Analysis of recent data on dairy cows in England and implications for the environment. http://www.defra.gov.uk/farm/policy/observatory/research/pdf/observatory03.pdf.

Duncan, A.L., 1990. Health security in cattle herds. In Practice 12, 29-32.

Gibbens, J.C., Sharpe, C.E., Wilesmith, J.W., Mansley, L.M., Michalopoulou, E., Ryan, J.B.M., Hudson, M., 2001. Descriptive epidemiology of the 2001 foot-and-mouth disease epidemic in Great Britain: the first five months. Vet. Rec. 149, 729-+.

Gilbert, M., Mitchell, A., Bourn, D., Mawdsley, J., Cliton-Hadley, R., Wint, W., 2005. Cattle movements and bovine tuberculosis in Great Britain. Nature 435, 491-496.

Hanneman, R.A., Riddle, M., 2005. Introduction to social network methods. Riverside CA: University of California Riverside, CA.

Jones, M., 1946. The Wintering of Hill Sheep. Proc. Nutr. Soc. 4, 58-64.

MAFF, 1998. Annex B - Sustainable Food and Farming: Economic Analysis and Evidence. www.defra.gov.uk/farm/policy/sustain/pdf/workingtogether-annexb.pdf.

Mikkelsen, T., Alexandersen, S., Astrup, P., Champion, H.J., Donaldson, A.I., Dunkerley, F.N., Gloster, J., Sorensen, J.H., Thykier-Nielsen, S., 2003. Investigation of airborne foot-andmouth disease virus transmission during low-wind conditions in the early phase of the UK 2001 epidemic. Atmos. Chem. Phys. 3, 2101-2110. 
Nielen, M., Jalvingh, A.W., Horst, H.S., Dijkhuizen, A.A., Maurice, H., Schut, B.H., vanWuijckhuise, L.A., deJong, M.F., 1996. Quantification of contacts between Dutch farms to assess the potential risk of foot-and-mouth disease spread. Prev. Vet. Med. 28, 143-158.

Ortiz-Pelaez, A., Pfeiffer, D.U., Soares-Magalhaes, R.J., Guitian, F.J., 2006. Use of social network analysis to characterize the pattern of animal movements in the initial phases of the 2001 foot and mouth disease (FMD) epidemic in the UK. Prev. Vet. Med. 76, 40-55.

Robinson, S.E., Christley, R.M., 2007. Exploring the role of auction markets in cattle movements within Great Britain. Prev Vet Med doi:10.1016/j.prevetmed.2007.04.011.

SAC, 2002. Herd biosecurity for cattle, Technical Note T502. http://www.sac.ac.uk/.

Sanson, R.L., Struthers, G., King, P., Weston, J.F., Morris, R.S., 1993. The Potential Extent of Transmission of Foot-and-Mouth-Disease - a Study of the Movement of Animals and Materials in Southland, New-Zealand. NZ. Vet. J. 41, 21-28.

Scherer, C.W., Cho, H.C., 2003. A social network contagion theory of risk perception. Risk Anal. 23, 261-267.

Sharma, S., 1996. Applied Multivariate Techniques. John Wiley and Sons Inc Canada.

van Schaik, G., Dijkhuizen, A.A., Huirne, R.B.M., Schukken, Y.H., Nielen, M., Hage, H.J., 1998. Risk factors for existence of Bovine Herpes Virus 1 antibodies on nonvaccinating Dutch dairy farms. Prev. Vet. Med. 34, 125-136.

Webb, C.R., 2005. Farm animal networks: unraveling the contact structure of the British sheep population. Prev. Vet. Med. 68, 3-17.

Woodroffe, R., Donnelly, C.A., Jenkins, H.E., Johnston, W.T., Cox, D.R., Bourne, F.J., Cheeseman, C.L., Delahay, R.J., Clifton-Hadley, R.S., Gettinby, G., Gilks, P., Hewinson, R.G., McInerney, J.P., Morrison, W.I., 2006. Culling and cattle controls influence tuberculosis risk for badgers. Proc. Natl. Acad. Sci. USA. 103, 14713-14717.

Woolhouse, M., Donaldson, A., 2001. Managing foot-and-mouth - The science of controlling disease outbreaks. Nature 410, 515-516.

Woolhouse, M.E.J., Shaw, D.J., Matthews, L., Liu, W.C., Mellor, D.J., Thomas, M.R., 2005. Epidemiological implications of the contact network structure for cattle farms and the 20-80 rule. Biol. Lett.-UK 1, 350-352. 
639 Tables

640 Table 1: Clusters M1-M3 identified by hierarchical cluster analyses based on animal

641 movement type using Ward's cluster method (significance determined using $\chi^{2}$ test) on

642 data collected in 2005 from 56 cattle farms in north-west England

\begin{tabular}{|c|c|c|c|c|}
\hline $\begin{array}{l}\text { Movement } \\
\text { type }\end{array}$ & $\begin{array}{c}\text { Group M1 } \\
(\% ; n=17)\end{array}$ & $\begin{array}{l}\text { Group M2 } \\
(\% ; \mathbf{n}=20)\end{array}$ & $\begin{array}{l}\text { Group M3 } \\
(\% ; n=19)\end{array}$ & P-value \\
\hline Buying from farms & 59 & 60 & 58 & 1.0 \\
\hline Hiring from farms & 12 & 25 & 0 & $0.06^{*}$ \\
\hline Selling to farms & 0 & 0 & 100 & $<0.001$ \\
\hline Hiring to farms & 0 & 0 & 5 & $0.4 *$ \\
\hline Trading with markets & 100 & 85 & 84 & $0.2 *$ \\
\hline $\begin{array}{l}\text { Trading through } \\
\text { dealers } \\
\text { Direct movement to } \\
\text { slaughterhouses }\end{array}$ & 59 & 100 & 42 & $<0.001$ \\
\hline
\end{tabular}

643

* Expected cell less than 5

644

645

646

647

648

649

650

651

652

653

654

655 
656 Table 2: Clusters CC1-CC3 identified by hierarchical cluster analyses using Ward's cluster

657 method based on companies and contractors visiting 56 cattle farms in north-west England in

658 2005 (significance determined using $\chi^{2}$ test)

\begin{tabular}{|c|c|c|c|c|}
\hline $\begin{array}{l}\text { Companies and } \\
\text { Contractors }\end{array}$ & $\begin{array}{c}\text { Group CC1 } \\
(\% ; n=19)\end{array}$ & $\begin{array}{c}\text { Group CC2 } \\
(\% ; n=24)\end{array}$ & $\begin{array}{c}\text { Group CC3 } \\
(\% ; n=13)\end{array}$ & P-value \\
\hline Milk company & 58 & 50 & 100 & 0.008 \\
\hline Government veterinarians & 58 & 4 & 15 & $<0.001 *$ \\
\hline Trading Standards & 47 & 0 & 39 & $0.001 *$ \\
\hline AI technician & 53 & 25 & 77 & 0.008 \\
\hline Animal haulier & 84 & 17 & 69 & $<0.001$ \\
\hline Deadstock collector & 95 & 100 & 100 & $0.4^{*}$ \\
\hline Muck spreaders & 63 & 71 & 92 & 0.2 \\
\hline Hoof trimmers & 16 & 8 & 100 & $<0.001$ \\
\hline Belly clippers & 0 & 0 & 7.7 & $0.2 *$ \\
\hline Castrators & 11 & 0 & 0 & $0.1 *$ \\
\hline Farm assurance advisors & 68 & 83 & 100 & $0.07 *$ \\
\hline Median no. animals per farm (IQR) & $151(92-280)$ & $140(92-322)$ & $238(164-367)$ & 0.2 \\
\hline Median hectarage of farm (IQR) & $59(32-113)$ & $59(47-123)$ & $117(86-182)$ & 0.03 \\
\hline
\end{tabular}

$659 *$ Expected cell less than 5

660

661

662

663

664

665

666

667

668

669

670 
671 Table 3: Matrix of relationships between contact types determined using QAP correlation from

672 information gathered from 56 cattle farms in north-west England during 2005. Values indicate

673 the probability of the observed similarities, under the null hypothesis of no correlation between

674 contact types.

\begin{tabular}{|c|c|c|c|c|c|c|c|c|c|c|c|c|}
\hline & 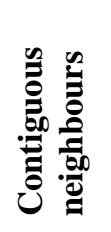 & 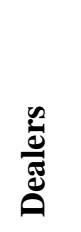 & 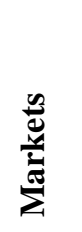 & 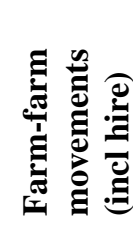 & 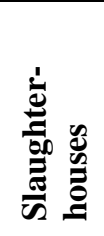 & 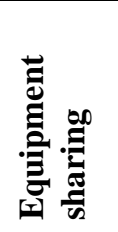 & そ & 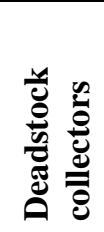 & 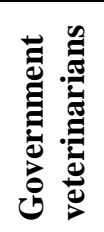 & 总 & 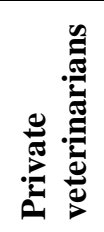 & \\
\hline \multicolumn{13}{|l|}{$\begin{array}{l}\text { Contiguous } \\
\text { neighbours }\end{array}$} \\
\hline Dealers & 0.1 & & & & & & & & & & & \\
\hline Markets & 0.01 & 0.81 & & & & & & & & & & \\
\hline $\begin{array}{l}\text { Farm-farm } \\
\text { movements (incl } \\
\text { hire) }\end{array}$ & 0.02 & 0.26 & 0.57 & & & & & & & & & \\
\hline Slaughterhouses & 0.31 & 0.76 & 0.88 & 1.00 & & & & & & & & \\
\hline Equipment sharing & $<0.001$ & 0.38 & 0.93 & 0.05 & 0.76 & & & & & & & \\
\hline AI technicians & 0.3 & 0.77 & 0.48 & 1.00 & 0.52 & 0.03 & & & & & & \\
\hline $\begin{array}{l}\text { Deadstock } \\
\text { collectors }\end{array}$ & 0.55 & 0.67 & 0.06 & $\mathbf{0 . 0 3}$ & 0.70 & 0.46 & 0.02 & & & & & \\
\hline $\begin{array}{l}\text { Government } \\
\text { veterinarians }\end{array}$ & 0.26 & 0.04 & 0.84 & 0.28 & 0.72 & 0.40 & 0.73 & 0.27 & & & & \\
\hline Milk companies & 0.01 & 0.76 & 0.24 & 1.00 & 0.08 & 1.00 & 0.002 & 0.14 & 0.93 & & & \\
\hline $\begin{array}{l}\text { Private } \\
\text { veterinarians }\end{array}$ & 0.13 & 0.68 & 0.20 & 0.60 & 0.65 & 0.54 & 0.12 & 0.83 & 0.62 & 0.43 & & \\
\hline Social interactions & $<0.001$ & 0.24 & 0.49 & $<0.001$ & 0.23 & $<0.001$ & 0.50 & 0.25 & 0.62 & 0.45 & 0.32 & \\
\hline
\end{tabular}

$675 \quad$ Values $<0.1$ are highlighted in bold

676

677

678

679

680

681

682

683 
684

685

686

687

688

689

690

691

692

693

694

695

696

697

698

699

700

701

702

703

704

705

706

707

\section{Figure captions}

Fig. 1: Schematic representation of potential contact characteristics of cattle farms

Fig. 2: 2-mode network of animal movements between interviewed cattle farms (circles, $n=55$ ) and markets (squares, $n=6$ ), dealers (triangles, $n=7$ ) and slaughterhouses (diamonds, $n=8$ ) in north-west England during 2005 (arranged using multi-dimensional scaling)

Fig. 3: (a) 1-mode network of animal movements between interviewed cattle farms (circles, $\mathrm{n}=39$ ) and other nominated farms (not interviewed) within the north-west England study area (triangles, $n=3$ ) and outside of the study area (squares, $n=39$ ) taken from information collected during 2005. (b) Network of animal movements as in Figure 6a excluding nominated farms outside of the study area

Fig. 4: Proportion of fencelines from a selection of boundary fences on 43 cattle farms within the north-west England study area allowing potential contact after farmers nominated them noncontact

Fig. 5: Network of equipment sharing between interviewed cattle farms (circles, $n=30$ ), other nominated farms within the north-west England study area (triangles, n=6) and outside of the study area (squares, $n=9)$ in 2005

Fig. 6: Number of visits per month by companies and contractors to each of the 56 cattle farms in the north-west England study area as nominated by farmers in 2005 
708

709 Fig. 7: (a) Network of private veterinarians $(n=6)$ and (b) animal hauliers $(n=18)$, and

710 interviewed cattle farms ( $n=56$ and 29 respectively) within the north-west England study area in

711 2005. In each case, the company or contractor (veterinarians or animal hauliers) are represented

712 by squares and the farms by circles

713

714

715

716

717

718

719

720

721

722

723

724

725

726

727

728

729

730 
731

732

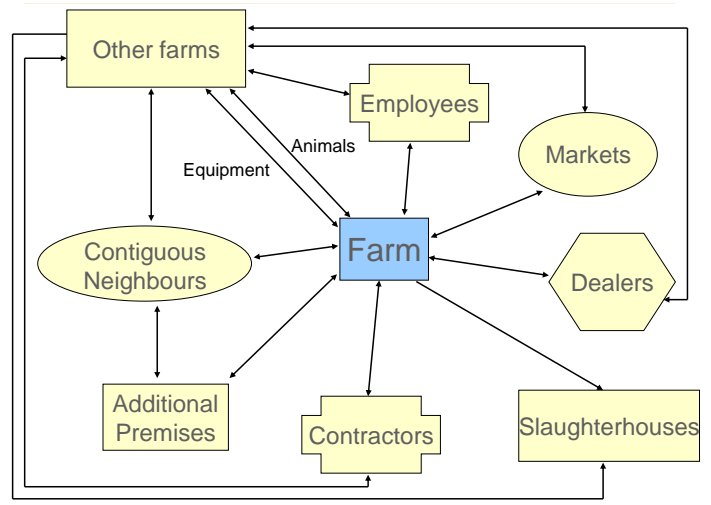

733

734

735

736

737

738

739

740

741

742

743

744

745

746

747

748

749

750 
751

752

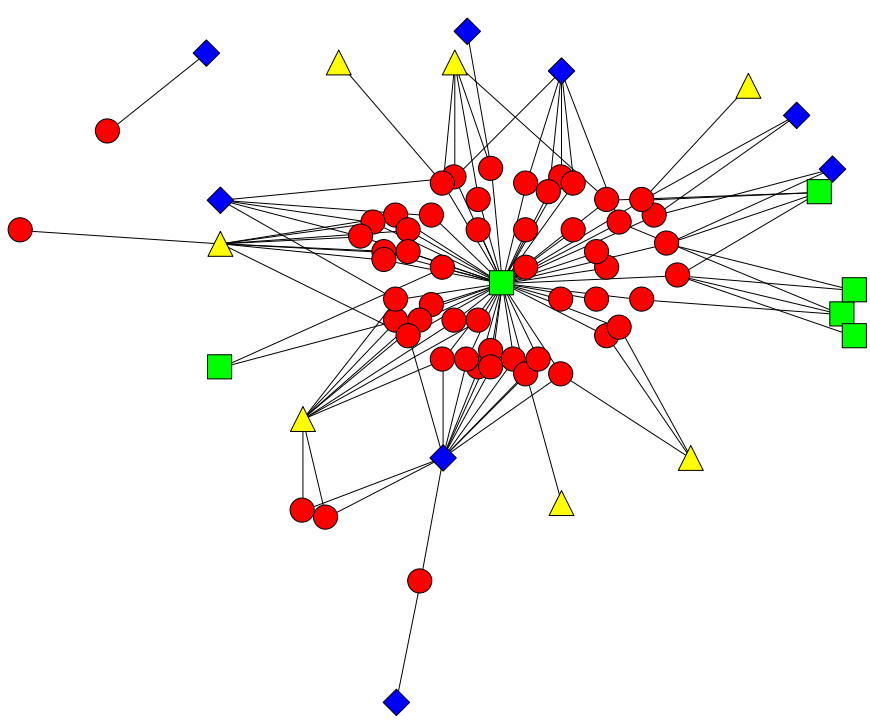

753

754

755

756

757

758

759

760

761

762

763

764

765

766

767

768 
769

770

(a)

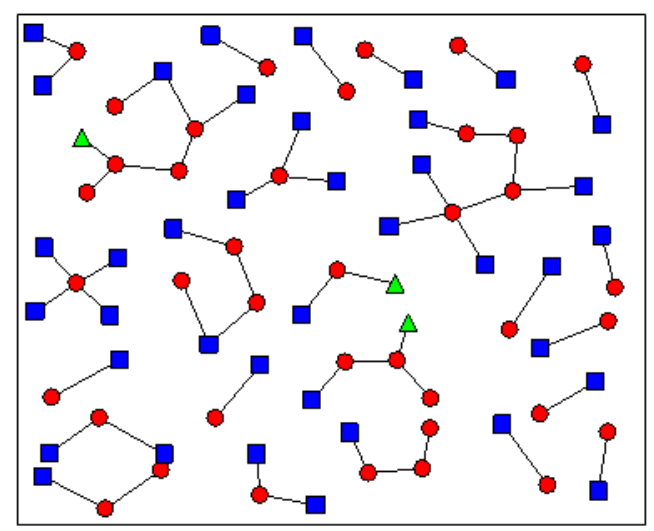

(b)

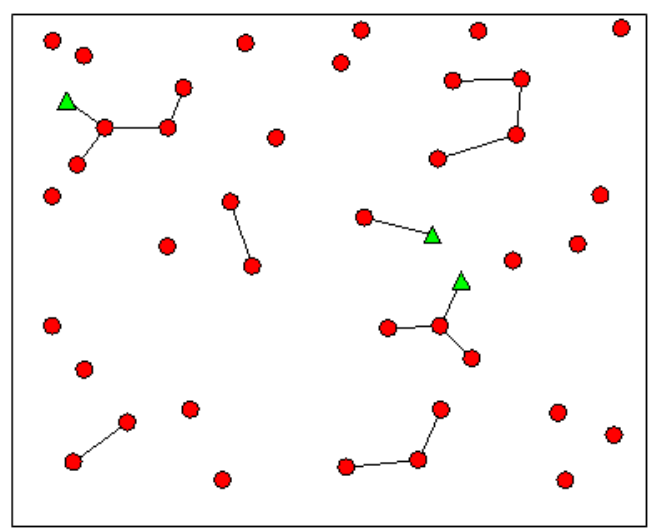

771

772

773

774

775

776

777

778

779

780

781

782

783

784

785

786

787

788 
789

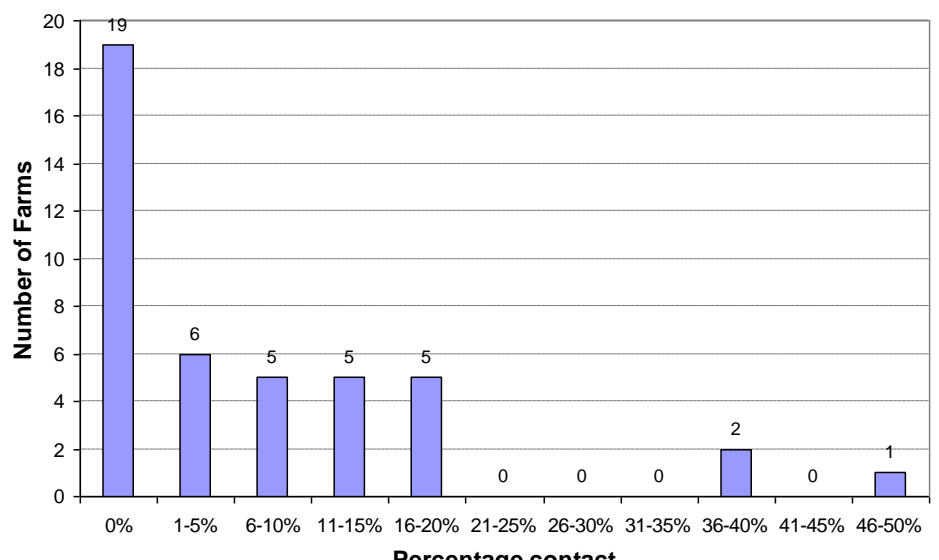

790 Percentage contact

791

792

793

794

795

796

797

798

799

800

801

802

803

804

805

806

807 
808

809

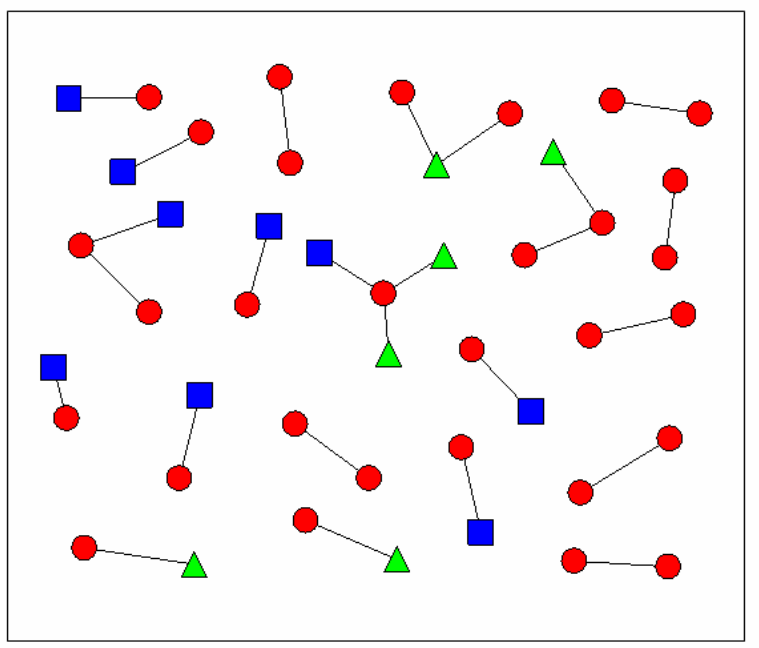

810

811

812

813

814

815

816

817

818

819

820

821

822

823

824

825

826 
827

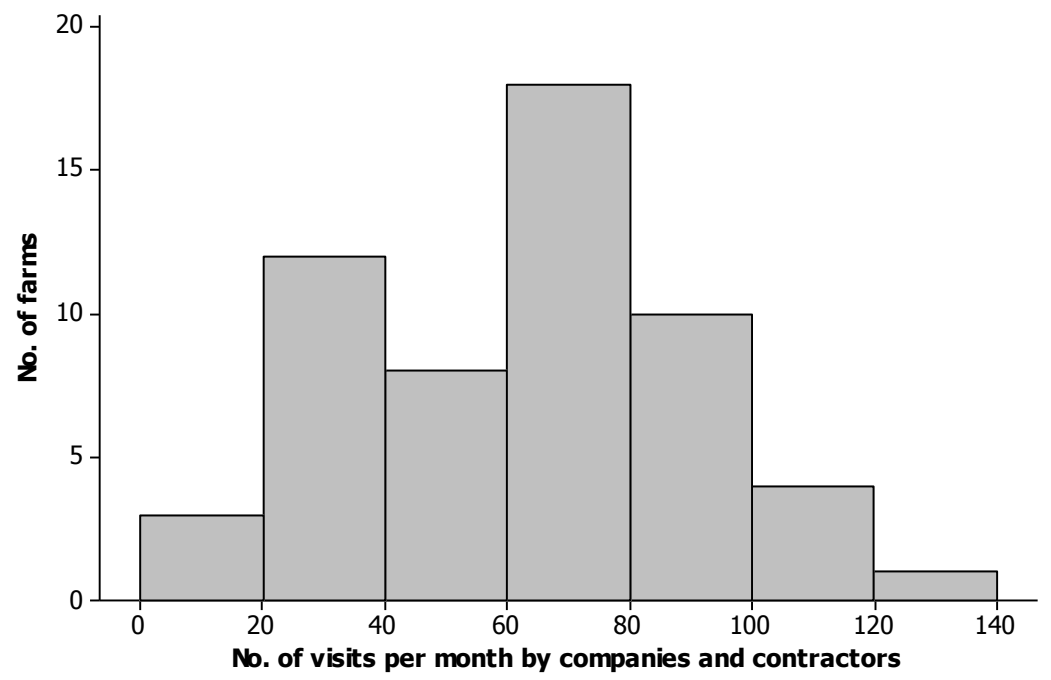

828

829

830

831

832

833

834

835

836

837

838

839

840

841

842

843

844 
845

(a)

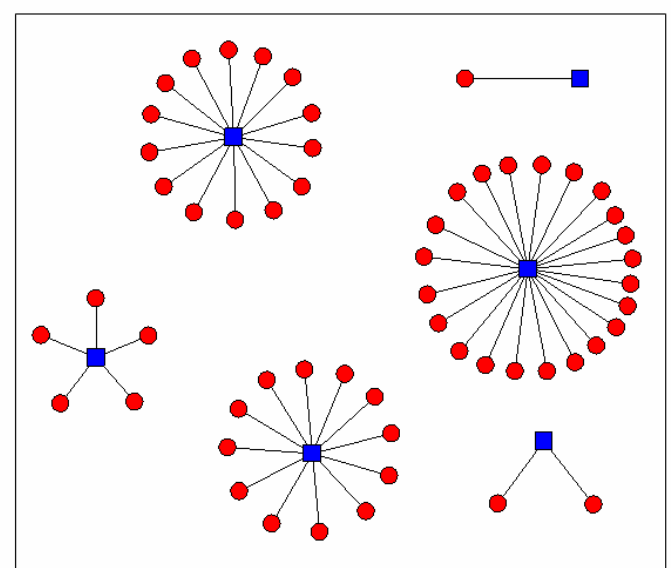

(b)

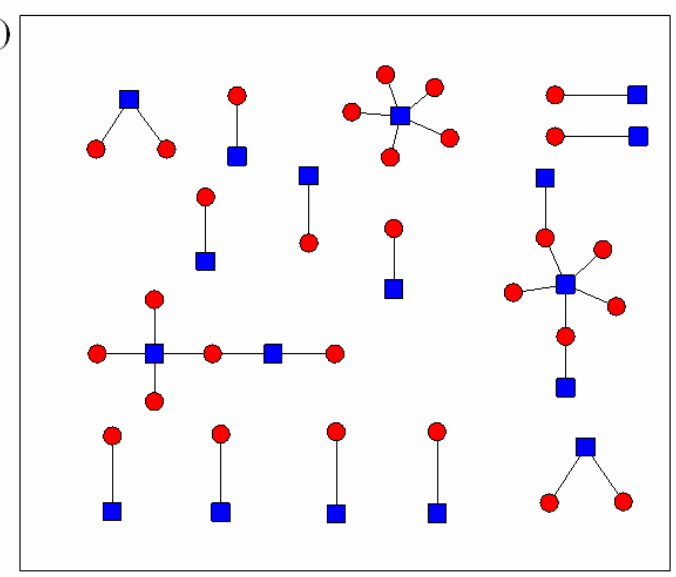

846

847

848

849

850

851

852

853

854

855

856

857

858

859

860

861

862

863 
864 Appendix A - List of companies and contractors

865

866

Milk company*

Private veterinarians*

867

Government veterinarians*

Trading standards*

868

AI technician*

Animal haulier*

869

Deadstock collector*

Vermin control

870

Castrators*

Feed/supplement suppliers

871

Muck spreaders*

Hoof trimmers*

872

Belly clippers*

Hedge trimmers

873

Silage makers

Planting/Harvesters

874

Farm assurance advisors*

Drug company reps

875

Fuel suppliers

Postman

876

Trades people

Others

877

*Indicates organisations classified as having access to animal areas

878

879

880

881

882

883

884

885

886

887

888 
889

890

891

892

893

894

895

896

897

898

899

900

901

902

903

904

905

906

907

908

909

910

911

912

913

\section{Appendix B - Biosecurity practices}

1) Maintaining a closed herd

2) Buying animals from a farm of known disease status

3) Isolating animals moved onto a farm (including show animals)

4) Testing animals which have moved on

5) Using your own vehicle when transporting animals

6) Cleaning and disinfecting vehicles after moving animals

7) Isolating sick animals

8) Minimising contact between your animals and animals on neighbouring farms e.g. double-fencing

9) Not grazing different species together

10) Fencing off stock access to streams and watercourses

11) Not grazing animals on pastures that have been recently spread with waste (or resting pastures for an appropriate period of time before moving animals on)

12) Locating animal loading areas away from where animals are situated

13) Minimising the number of visitors to the farm by improving security (closing gates, seeing visitors by appointment only etc)

14) Ensuring visitors change or clean clothes and boots before and after coming into contact with stock or stock areas

15) Encouraging vehicles to park away from stock areas

16) Seeking regular advice from vets or herd health schemes on herd issues

17) Regularly carrying out pest control

18) Minimising the sharing of equipment and machinery with other farms

19) Minimising the use of equipment and machinery for different purposes to avoid contamination e.g. avoiding feeding with vehicles used for muck handling 